\title{
Exclusion of COL2A1 as a candidate gene in a family with Wagner-Stickler syndrome
}

\author{
A E Fryer, M Upadhyaya, M Littler, P Bacon, D Watkins, P Tsipouras, P S Harper
}

\begin{abstract}
A large family with Wagner's vitreoretinal degeneration but none of the non-ocular features of Stickler's syndrome has been studied with gene probes for type II collagen. Recombination has been observed, thus excluding type II collagen as the site of mutation in this family. This report supports other published evidence that the WagnerStickler syndrome is genetically heterogeneous.
\end{abstract}

In 1938, Wagner ${ }^{1}$ described a family where 13 members in three generations had a vitreoretinal degeneration associated with myopia and cataracts. The only non-ocular feature reported was hearing loss in a 17 year old patient. The pattern of inheritance was autosomal dominant. Jansen ${ }^{2}$ later reported a similar phenotype in two Dutch families, but in some of these cases retinal detachments and simple glaucoma occurred. In 1963, Delaney $e t a l^{3}$ described a family where cleft palate was associated with the ocular changes and in 1965 Stickler $e t a l^{4}$ noted an association with craniofacial abnormalities and a progressive arthropathy. In several subsequent studies, patients with Wagner's retinopathy were shown to have some of the non-ocular features of Stickler's syndrome. Liberfarb et $a l^{5}$ studied 22 probands with Wagner's retinopathy and 68 of their relatives and found, in total, 70 affected subjects. Of these, $86 \%$ had the facial features of Stickler's syndrome and $60 \%$ had musculoskeletal abnormalities. They termed the dis-

Institute of Medical Genetics, University Hospital of Wales, Heath Park, Cardiff CF4 4XW.

A E Fryer, M Upadhyaya, $M$ Littler, P S Harper

Department of Ophthalmology, University Hospital of Wales, Cardiff.

P Bacon

Department of Pediatrics, University of Connecticut

Health Center, Farmington, CT 06032, USA.

D Watkins, P'Tsipouras

Correspondence to Dr Fryer

Received for publication 11 July 1989

Revised version accepted for publication 21 August 1989. order the Wagner-Stickler syndrome, concluding that the two phenotypes were part of the same condition.

An alternative approach was adopted by Maumenee ${ }^{6}$ who subdivided 'Wagner-like vitreoretinal degeneration' according to the associated clinical features. She first grouped families into those with and those without non-ocular manifestations. The first group included families like those described by Wagner ${ }^{1}$ and Jansen. ${ }^{2}$ The second group contained several bone dysplasias and included Stickler's syndrome. Maumenee suggested that families in this latter group may result from mutations involving type II collagen as this is present in the secondary vitreous and cartilage. This view gained support when genetic linkage was shown to the structural gene for type II collagen (COL2A1) in two families with Stickler's syndrome.?

This discovery provides a means of determining whether all vitreoretinal degenerations result from mutations at the same locus or whether the clinical subdivision of Maumenee has a basis in non-allelic genetic heterogeneity. We have studied a family where the clinical features have been purely ocular and where several members have had retinal detachments. This family therefore most resembles that described by Jansen. ${ }^{2}$ We have looked for genetic linkage in this family to the collagen probe COL2A 1 . If recombination is detected then a mutation in the type II collagen gene is excluded as the cause for the disorder in this family.

Families that have been reported with the WagnerStickler syndrome have shown considerable variability in the expression of the gene. Liberfarb et $a l^{5}$ found no evidence of skipped generations in 22 families and so penetrance appears to be nearly complete, but in view of the variability they recommended that routine eye examinations had to be performed into the third decade before the diagnosis of Wagner's syndrome could be ruled out with certainty.

\section{Methods}

The pedigree is shown in the figure and the clinical features of the affected subjects are recorded in the table. All of the living patients have been examined by 


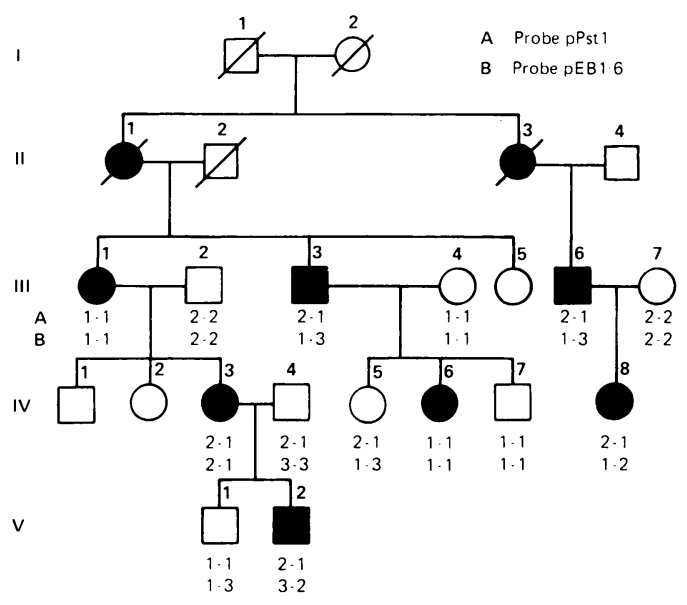

Pedigree with typing results.

Clinical features of affected subjects.

II.1 History of myopia. Glaucoma aged $45 \mathrm{y}$.

II. 3 History of retinal detachment at $23 \mathrm{y}$. Later developed glaucoma and became blind.

III.1 Aged 59 y. Myopia, wearing spectacles from 4 y. Glaucoma at 36 y. Subsequently developed bilateral cataracts and a retinal detachment. Registered blind at $56 \mathrm{y}$.

III. 3 Aged 55 y. Strabismus in early childhood. Glaucoma aged $44 \mathrm{y}$.

III.6 Aged 53 y. High myopia in childhood. Glaucoma aged $32 \mathrm{y}$. Cataract and detached left retina subsequently.

IV.3 Aged 35 y. Myopia, wearing spectacles from 7 y. Retinal detachment aged $18 \mathrm{y}$.

IV.6 Aged 28 y. Small retinal tear. Hypermetropia.

IV.8 Congenital glaucoma.

V.2 Aged 8 y. Myopia, spectacles from 4 y. Recurrent retinal detachments from age $5 \mathrm{y}$.

ophthalmologists and have characteristic fundal signs. In order to avoid misclassification of unaffected persons, those clinically normal subjects over 20 years of age who were available for study (IV.5 and IV.7) had ophthalmological examinations (by PB) involving Goldmann aplanation tonometry, slit lamp examination, indirect ophthalmoscopy, and three mirror biomicroscopy.

Blood was taken from all living subjects in the pedigree and DNA preparation, restriction enzyme digests, electrophoresis, and Southern transfer performed using standard methods. The filters were hybridised with the DNA probes pPstl (kindly provided by Dr Ellen Solomon) and pEB1.6. Probe pPstl is a subclone of CosHcol 1 that contains the human $\alpha 1$ (II) collagen gene and is a $1.1 \mathrm{~kb}$ fragment. ${ }^{8}$ This probe detects a HindIII polymorphism consisting of a $7.0 \mathrm{~kb}$ and a $14.0 \mathrm{~kb}$ band. Probe pEB1.6 is a $1.6 \mathrm{~kb}$ EcoRI-BglII fragment of HCOLIIF ${ }^{9} 10$ and maps to $12 \mathrm{q} 13.1 \mathrm{q} 13.2$. This probe detects a HinfI polymorphism and identifies a three allele system (allele $1=2.1 \mathrm{~kb}, 2=1.75 \mathrm{~kb}$, and $3=1.15$ and $0.6 \mathrm{~kb}$ ) with allele frequencies $0 \cdot 44,0 \cdot 11$, and 0.45 .

\section{Results}

The DNA typing results are given in the figure. Phase is established for both probes in III.1. With probe $\stackrel{D}{工}$ pPst 1, IV.7 and V.1 are recombinants. IV.7 has had a $\stackrel{\mathbb{D}}{\rightarrow}$ full ophthalmological assessment at 23 years of age $\overrightarrow{\vec{F}}$ and has no signs of the disorder. V.1 is only 11 years of age, and hence we cannot be certain that he is unaffected. With probe pEB1.6, the affected subject V.2 is also a recombinant. IV.5 (aged 30 years) also had a full ophthalmological assessment and no abnormalities were detected.

\section{Discussion}

Francomano et $a l^{7}$ have presented evidence from a linkage study to support the hypothesis that mutations in type II collagen cause at least some cases of Stickler's syndrome. There has been a debate about the possible identity or allelism of Wagner's and Stickler's syndromes, and linkage studies in families with these diagnoses can help resolve this issue. It is $\mathrm{O}$ clear from clinical and radiological studies that many families labelled as Wagner's syndrome have the additional features of Stickler's syndrome. Members of this family, however, fulfil the criteria of Wagner or Jansen retinopathy, but no family members have the typical facial features or marfanoid habitus of $\overline{0}$ Stickler's syndrome nor the associated spondyle epiphyseal dysplasia (II.1, III.3, and IV.2 have hag skeletal $x$ rays). There is also no history or signs oral clefting or deafness. Three recombinants have been observed in this family with COL2A1 gene probes, although one of these subjects (V.1) is only 11 years of age and so this conclusion might be deferred. This result shows that the mutation in this family is not within the type II collagen structural gene.

Since the publication of the original linkage data by Francomano $\mathrm{et} \mathrm{al},{ }^{7}$ the same authors have studied the original family reported by Wagner and excluded mutations at the $C O L 2 A 1$ locus. ${ }^{11}$ The results reported here, in a family that clinically most closely resembles the one described by Jansen, ${ }^{2}$ provide further evidence that the vitreoretinal degeneration of Wagner is genetically heterogeneous. The defect here is not within the structural gene for type II collagen, though conceivably the defect may reflect a mutation involving post-transcriptional or post-translational modification.

We would like to thank Mr Laz Lazarou for technical assistance.

1 Wagner H. Ein bisher unbekanntes Erbliden des Auges (Degeneratio hyaloideo-retinalis hereditaria), beobachtet in Kanton $\square$ Zurich. Klin Monastbl Augenheilkd 1938;100:840-57.

2 Jansen LMAA. Degeneratio hyaloideo-retinalis hereditaria. Ophthalmologica 1962;144:458-64. 
3 Delaney WV, Podedworny W, Havener WH. Inherited retinal detachment. Arch Ophthalmol 1963;69:44-50.

4 Stickler GB, Belau PG, Farrell FJ, et al. Hereditary progressive arthroophthalmopathy. Mayo Clin Proc 1965;40:433-55.

5 Liberfarb RM, Hirose T, Holmes LB. The Wagner-Stickler syndrome: a study of 22 families. 7 Pediatr 1981;99:394-9.

6 Maumenee IR. Vitreoretinal degeneration as a sign of generalised connective tissue disease. Am f Ophthalmol 1979;88:432-49.

7 Francomano CA, Liberfarb RM, Hirose T, et al. The Stickler syndrome: evidence for close linkage to the structural gene for type II collagen. Genomics 1987;1:293-6.
8 Sykes B. A high frequency Hind III restriction site polymorphism within a collagen gene. Disease Markers 1983;1:141-6.

9 Sangiorgi FO, Benson-Chanda V, de Wet WJ, Sobel ME, Tsipouras P, Ramirez F. Isolation and partial characterisation of the entire human procl(II) collagen gene. Nucleic Acids Res 1985;13:2207-25.

10 Strom CM. A three allele restriction fragment length polymorphism within human Col2A1 gene. Nucleic Acids Res 1988;16:9077.

11 Francomano CA, Rowan BG, Liberfarb RM, et al. The Stickler and Wagner syndromes: evidence for genetic heterogeneity. Am $\mathcal{F}$ Hum Genet 1988;43(suppl 3):83A. 